\title{
Post hoc analyses of data from a 90-day clinical trial evaluating the tolerability and efficacy of tapentadol immediate release and oxycodone immediate release for the relief of moderate to severe pain in elderly and nonelderly patients
}

\author{
Gary Vorsanger $\mathrm{PhD} \mathrm{MD}^{1}$, Jim Xiang $\mathrm{PhD}^{1}$, David Biondi $\mathrm{DO}^{1}$, David Upmalis $\mathrm{MD}^{2}$, \\ Jacqueline Delfgaauw $\mathrm{PhD}^{3}$, René Allard $\mathrm{PhD}^{4}$, Bruce Moskovitz $\mathrm{MD}^{1}$
}

\begin{abstract}
G Vorsanger, J Xiang, D Biondi, et al. Post hoc analyses of data from a 90-day clinical trial evaluating the tolerability and efficacy of tapentadol immediate release and oxycodone immediate release for the relief of moderate to severe pain in elderly and nonelderly patients. Pain Res Manage 2011;16(4):245-251.
\end{abstract}

OBJECTIVE: To evaluate the tolerability and efficacy of tapentadol immediate release (IR) and oxycodone IR for relief of moderate to severe pain in elderly and nonelderly patients.

METHODS: Post hoc data analyses were conducted on a 90-day randomized, phase 3, double-blind, flexible-dose study (ClinicalTrials.gov: NCT00364546) of adults with moderate to severe lower back pain or osteoarthritis pain who received tapentadol IR $50 \mathrm{mg}$ or $100 \mathrm{mg}$, or oxycodone $\mathrm{HCl}$ IR $10 \mathrm{mg}$ or $15 \mathrm{mg}$ every $4 \mathrm{~h}$ to $6 \mathrm{~h}$ as needed for pain relief. Treatment-emergent adverse events and study discontinuations were recorded.

RESULTS: Data from 849 patients randomly assigned (4:1 ratio) to treatment with a study drug (tapentadol IR [ $\mathrm{n}=679]$ or oxycodone IR [ $\mathrm{n}=170]$ ) were analyzed according to age (younger than 65 years of age [nonelderly], or 65 years of age or older [elderly]) and treatment group. Among elderly patients, incidences of constipation $(19.0 \%$ versus $35.6 \%)$ and nausea or vomiting $(30.4 \%$ versus $51.1 \%)$ were significantly lower with tapentadol IR versus oxycodone IR (all $\mathrm{P}<0.05$ ). Initial onsets of nausea and constipation occurred significantly later with tapentadol IR versus oxycodone IR (both P $\leq 0.031$ ). Tapentadol IR-treated elderly patients had a lower percentage of days with constipation than oxycodone IR-treated patients $(\mathrm{P}=0.020)$. For tapentadol IR- and oxycodone IR-treated elderly patients, respectively, incidences of study discontinuation due to gastrointestinal treatment-emergent adverse events were $15.8 \%$ and $24.4 \%(\mathrm{P}=0.190)$. Tapentadol IR and oxycodone IR provided similar pain relief, with no overall age-dependent efficacy differences (mean pain scores [11-point numerical rating scale] decreased from 7.0 and 7.2 at baseline, to 4.9 and 5.2 at end point, respectively).

CONCLUSIONS: Tapentadol IR was safe and effective for the relief of lower back pain and osteoarthritis pain in elderly patients, and was associated with a better gastrointestinal tolerability profile than oxycodone IR.

Key Words: Analgesia; Elderly; Opioid; Pain management; Tapentadol IR
Des analyses a posteriori de données tirées d'un essai clinique de 90 jours évaluant la tolérabilité et l'efficacité du tapentadol à libération immédiate et de l'oxycodone à libération immédiate pour soulager une douleur modérée à grave chez des patients âgés et non âgés

OBJECTIF : Évaluer la tolérabilité et l'efficacité du tapentadol à libération immédiate (LI) et de l'oxycodone à LI pour soulager une douleur modérée à grave chez des patients âgés et non âgés.

MÉTHODOLOGIE : Les chercheurs ont procédé à des analyses de données a posteriori à l'égard d'une étude aléatoire à double insu et à doses flexibles de phase 3 d'une durée de 90 jours (ClinicalTrials.gov: NCT00364546) auprès d'adultes ayant des douleurs lombaires modérées à graves ou des douleurs causées par l'arthrose et qui prenaient soit $50 \mathrm{mg}$ ou $100 \mathrm{mg}$ de tapentadol à LI, soit $10 \mathrm{mg}$ ou $15 \mathrm{mg}$ de chlorydrate d'oxycodone à LI toutes les quatre à six heures, au besoin, pour soulager la douleur. Ils ont pris note des effets indésirables se déclarant pendant le traitement ainsi que des études interrompues.

RÉSULTATS: Les chercheurs ont analysé les données de 849 patients répartis au hasard (ratio de 4:1) entre un traitement avec un médicament à l'étude (tapentadol à LI [n=679] ou oxycodone à LI [n=170]) selon l'âge (moins de 65 ans [non âgés], ou 65 ans ou plus [âgés]) et le groupe de traitement. Chez les patients âgés, l'incidence de constipation (19,0\% par rapport à 35,6 \%) et de nausées ou vomissements $(30,4 \%$ par rapport à $51,1 \%)$ était considérablement plus faible dans le groupe prenant du tapentadol à LI que dans celui prenant de l'oxycodone à LI $(\mathrm{P}<0,05$ dans tous les cas). L'apparition initiale de nausées et de constipation se produisait beaucoup plus tard avec le tapentadol à LI qu'avec l'oxycodone à $\mathrm{LI}$ $(\mathrm{P} \leq 0,031$ dans les deux cas). Le patients âgés traités au tapentadol à $\mathrm{LI}$ étaient constipés pendant un moins grand pourcentage de jours que ceux qui étaient traités à l'oxycodone à LI $(\mathrm{P}=0,020)$. Chez les patients âgés traités au tapentadol à LI et à l'oxycodone à LI, respectivement, l'incidence d'études interrompues en raison d'effets indésirables émergents de nature gastro-intestinale s'élevait à $15,8 \%$ et à $24,4 \%(\mathrm{P}=0,190)$. Le tapentadol à LI et l'oxycodone à LI procuraient un soulagement similaire de la douleur, sans différences globales d'efficacité selon l'âge (indices de douleur moyens [échelle d'évaluation numérique de 11 points] fléchissant de 7,0 et 7,2 au départ à 4,9 et 5,2 à la fin de l'étude, respectivement).

CONCLUSION : Le tapentadol à LI était sécuritaire et efficace pour soulager les douleurs lombaires et la douleur causée par l'arthrose chez les patients âgés et s'associait à un meilleur profil de tolérabilité gastrointestinale que l'oxycodone à LI.

\footnotetext{
${ }^{1}$ Janssen Scientific Affairs, LLC, Raritan, New Jersey, USA; ${ }^{2} J o h n s o n ~ \mathcal{E}$ Johnson Pharmaceutical Research $\mathcal{E}$ Development, L.L.C., Raritan, New Jersey, USA; ${ }^{3}$ US Development Medical Sciences, Grünenthal USA, Inc, Bedminster, New Jersey, USA; ${ }^{4}$ Global Medical Science, Grünenthal GmbH, Aachen, Germany

Correspondence: Dr Gary Vorsanger, Clinical Development, Janssen Scientific Affairs, LLC, 1000 Route 202 South, Raritan, New Jersey 08869, USA. Telephone 908-927-5469, fax 908-218-1286, e-mail gvorsang@its.jnj.com
} 
Tn the United States, more than $20 \%$ of people 60 years of age or older experience persistent back, arthritis or joint pain (1). Population-based studies indicate that pain-related problems are present in an estimated $25 \%$ to $50 \%$ of elderly people living in the community and $40 \%$ to $80 \%$ of elderly people in nursing homes (1-3). Painful conditions often require treatment with strong analgesics (4-6); however, pain experienced by elderly people is often not effectively detected and diagnosed, which may contribute to the inadequate management of pain within this patient population $(2,7)$. In addition, elderly patients are more likely to experience adverse effects associated with analgesic treatment compared with younger patients (8).

mu-Opioid ( $\mu$-opioid) receptor agonists are often used for the management of moderate to severe pain; however, opioid-related adverse effects - especially gastrointestinal- and central nervous system-related side effects $(9,10)$ - may limit the usefulness of these drugs in providing effective pain relief. Opioid-related side effects may be particularly problematic among elderly people, who already experience a higher rate of constipation (11) and a higher overall incidence of drug-related side effects than younger patients (3). The American Geriatrics Society recently issued guidelines for the pharmacological management of pain in older patients (12), with a specific focus on patients who are 75 years of age or older. These guidelines recommend that "clinicians who prescribe opioids should anticipate, assess, and identify potential opioid-associated adverse effects....and should reassess patients for ongoing attainment of therapeutic goals, adverse effects, and safe and responsible medication use" (12).

Tapentadol is a centrally acting analgesic with two mechanisms of action: $\mu$-opioid receptor agonism and noradrenaline reuptake inhibition (13). In patients with moderate to severe acute postoperative pain following bunionectomy $(14,15)$ and in patients with moderate to severe pain associated with end-stage degenerative joint disease of the hip or knee (16), tapentadol immediate release (IR) ( $50 \mathrm{mg}, 75 \mathrm{mg}$ or $100 \mathrm{mg}$ every $4 \mathrm{~h}$ to $6 \mathrm{~h}$ ) was shown to be associated with a better gastrointestinal tolerability profile compared with oxycodone $\mathrm{HCl}$ IR (10 mg or $15 \mathrm{mg}$ every $4 \mathrm{~h}$ to $6 \mathrm{~h}$ ). These doses of tapentadol IR and oxycodone IR provide similar analgesic efficacy.

A phase 3 randomized, double-blind, flexible-dose study (17) evaluated the safety and efficacy of tapentadol IR and oxycodone IR over 90 days for patients with moderate to severe chronic lower back pain or osteoarthritis pain of the knee or hip who required treatment for the relief of acute pain. Results of that study showed that although the use of tapentadol IR (50 mg or $100 \mathrm{mg}$ every $4 \mathrm{~h}$ to $6 \mathrm{~h}$ ) or oxycodone $\mathrm{HCl}$ IR (10 mg or $15 \mathrm{mg}$ every $4 \mathrm{~h}$ to $6 \mathrm{~h}$ ) resulted in similar reductions in pain scores, tapentadol IR was associated with lower incidences of the gastrointestinal treatment-emergent adverse events (TEAEs) of nausea, vomiting and constipation compared with oxycodone IR (17). The present article describes the results of post hoc analyses of data from that study (17), which examined the tolerability and efficacy of tapentadol IR and oxycodone IR in patients younger than 65 years of age (nonelderly) and patients 65 years of age or older (elderly) with moderate to severe lower back pain or osteoarthritis pain of the knee or hip.

\section{METHODS}

\section{Patient population}

A previous randomized, double-blind, active-controlled, parallelgroup 90 -day safety study (17) of tapentadol IR (50 mg or $100 \mathrm{mg}$ every $4 \mathrm{~h}$ to $6 \mathrm{~h}$ as needed) or oxycodone $\mathrm{HCl}$ IR (10 $\mathrm{mg}$ or $15 \mathrm{mg}$ every $4 \mathrm{~h}$ to $6 \mathrm{~h}$ as needed) enrolled men and women who were at least 18 years of age with moderate to severe lower back pain or osteoarthritis pain of the knee or hip. Detailed inclusion and exclusion criteria have been described previously (17) and are summarized here. Eligible patients experienced moderate to severe pain for at least three months before enrollment, with a baseline pain intensity of at least 4 on an 11-point numerical rating scale (ranged from 0 [no pain] to 10 [pain as bad as you can imagine]) while taking nonopioid analgesics or following a $24 \mathrm{~h}$ washout of opioid analgesics. Eligible patients required daily doses of analgesia for treatment of chronic pain, which may have consisted of nonsteroidal anti-inflammatory drugs or opioids (equivalent to $80 \mathrm{mg}$ or more of oral morphine per day) taken alone or in combination for at least 30 days before enrollment. Stable regimens of nonopioid analgesics were continued throughout the study.

Patients were excluded if they received treatment with monoamine oxidase inhibitors, tricyclic antidepressants or neuroleptics within two weeks of screening or had active autoimmune inflammatory conditions or clinically relevant disorders with the potential to confound safety or efficacy evaluations. During the course of the study, the use of selective serotonin reuptake inhibitors and selective noradrenaline reuptake inhibitors was permitted, provided they were taken at a stable dose for at least 30 days before the screening period.

\section{Study design}

Post hoc analyses were conducted using data from a randomized, doubleblind, active-controlled, parallel-group, multicentre, flexible-dose study (ClinicalTrials.gov identifier: NCT00364546) (17). The study consisted of three periods: a screening period of up to 28 days, with a $24 \mathrm{~h}$ washout period immediately preceding the baseline visit; a 90 -day double-blind treatment period; and an end-of-treatment visit, with a follow-up visit two to four days after the end-of-treatment visit. Patients were randomly assigned (4:1 ratio) to receive tapentadol IR ( $50 \mathrm{mg}$ or $100 \mathrm{mg}$; up to $600 \mathrm{mg} /$ day [n=679]) or oxycodone $\mathrm{HCl} \mathrm{IR}$ ( $10 \mathrm{mg}$ or $15 \mathrm{mg}$; up to $90 \mathrm{mg} /$ day $[\mathrm{n}=170]$ ) every $4 \mathrm{~h}$ to $6 \mathrm{~h}$ as needed for pain relief. Patients who were receiving nonopioid analgesics at the time of study entry (stable doses for at least 30 days before screening) were allowed to continue the same regimen during the study. Rescue analgesics (ie, up to $2000 \mathrm{mg} /$ day of oral acetaminophen or up to $400 \mathrm{mg} /$ day of oral ibuprofen) were allowed for no more than three days each week while patients were receiving the study medication.

Pain intensity scores were recorded at scheduled study visits on days $1,15,29,43,57,71$ and 91 of the double-blind treatment period; patients rated their average pain intensity over the previous $24 \mathrm{~h}$ using an 11-point numerical rating scale. Adverse events (AEs) were monitored and recorded from the screening visit through the follow-up (final) visit. The clinical intensity of an AE was classified as mild (symptoms that can be easily tolerated and ignored, and can disappear when the patient is distracted), moderate (symptoms that are tolerable but cause discomfort, cannot be ignored and affect concentration) or severe (symptoms that affect usual daily activities) according to the judgement of the investigator. TEAEs were defined as AEs that were new or that worsened after administration of the first dose of the study drug.

\section{Post hoc statistical analysis}

Analyses were performed on the safety (intent-to-treat) population, which was defined as all randomized patients who received at least one dose of a study medication. Between-group differences in demographic and baseline characteristics, pain intensity scores and treatment exposure were evaluated using descriptive statistics for patients divided according to treatment group and age group (younger than 65 years of age [nonelderly] or 65 years of age or older [elderly]) $(18,19)$. P values were determined using a one-way ANOVA with treatment as the factor for continuous variables and Fisher's exact test for comparison of sex and pain intensity category at random assignment. Pearson's $\chi^{2}$ test was used for comparison of age group and race.

Between-group differences in the incidence of selected TEAEs, rates of discontinuation due to TEAEs and rates of discontinuation when a specific TEAE was identified as the cause were compared using Fisher's exact test. Kaplan-Meier plots were used to estimate the time to discontinuation due to a TEAE (treatment and age group differences were compared using the log-rank test). Exploratory analyses were performed to investigate the influence of age on the incidence of TEAEs and study discontinuations due to TEAEs. No multiplicity adjustments 
TABLE 1

Baseline demographic and clinical characteristics

\begin{tabular}{|c|c|c|c|c|}
\hline \multirow[b]{3}{*}{ Characteristic } & \multicolumn{2}{|c|}{$<65$ years of age } & \multicolumn{2}{|c|}{$\geq 65$ years of age } \\
\hline & \multicolumn{2}{|c|}{$\overline{\text { Tapentadol Oxycodone }}$} & \multicolumn{2}{|c|}{ Tapentadol Oxycodone } \\
\hline & IR $(n=521)$ & IR (n=125) & IR ( $(n=158)$ & IR (n=45) \\
\hline Age, years & $51.1 \pm 8.9$ & $51.4 \pm 9.4$ & $71.7 \pm 5.3$ & $70.2 \pm 5.0$ \\
\hline \multicolumn{5}{|l|}{ Age category, years } \\
\hline$<65$ & $521(100.0)$ & $125(100.0)$ & $0(0)$ & $0(0)$ \\
\hline$\geq 65$ to $<75$ & $0(0)$ & $0(0)$ & $114(72.2)$ & $36(80.0)$ \\
\hline$\geq 75$ & $0(0)$ & $0(0)$ & $44(27.8)$ & $9(20.0)$ \\
\hline \multicolumn{5}{|l|}{ Sex } \\
\hline Female & $286(54.9)$ & $70(56.0)$ & $85(53.8)$ & $25(55.6)$ \\
\hline Male & $235(45.1)$ & $55(44.0)$ & $73(46.2)$ & $20(44.4)$ \\
\hline \multicolumn{5}{|l|}{ Race } \\
\hline White & $432(82.9)$ & $101(80.8)$ & $142(89.9)$ & $37(82.2)$ \\
\hline Black & 62 (11.9) & $17(13.6)$ & $15(9.5)$ & $7(15.6)$ \\
\hline Hispanic & $15(2.9)$ & $4(3.2)$ & $0(0)$ & $1(2.2)$ \\
\hline Other & $12(2.3)$ & $3(2.4)$ & $1(0.6)$ & $0(0)$ \\
\hline Body weight, $\mathrm{kg}$ & $93.2 \pm 24.0$ & $91.5 \pm 22.8$ & $86.2 \pm 19.8$ & $87.9 \pm 20.7$ \\
\hline BMI, $\mathrm{kg} / \mathrm{m}^{2}$ & $32.2 \pm 7.65$ & $32.3 \pm 8.14$ & $30.6 \pm 6.25$ & $30.5 \pm 6.73$ \\
\hline Pain intensity rating & $7.07 \pm 1.55$ & $7.14 \pm 1.29$ & $6.96 \pm 1.76$ & $7.24 \pm 1.69$ \\
\hline \multicolumn{5}{|l|}{ Pain intensity category } \\
\hline Moderate* & $90(17.3)$ & $16(12.8)$ & $38(24.1)$ & $8(17.8)$ \\
\hline Severe $^{\dagger}$ & $431(82.7)$ & $109(87.2)$ & $120(75.9)$ & 37 (82.8) \\
\hline \multicolumn{5}{|l|}{ Concomitant medications } \\
\hline All & $502(96.4)$ & $113(90.4)$ & $153(96.8)$ & $43(95.6)$ \\
\hline Analgesics, nonopioid & $371(71.2)$ & $81(64.8)$ & $116(73.4)$ & $28(62.2)$ \\
\hline Analgesics, opioid & $39(7.5)$ & $9(7.2)$ & $12(7.6)$ & $2(4.4)$ \\
\hline $\begin{array}{c}\text { All, excluding } \\
\text { analgesics }\end{array}$ & $441(84.6)$ & $101(80.8)$ & $152(96.2)$ & $43(95.6)$ \\
\hline
\end{tabular}

Data presented as mean $\pm S D$ or $n$ (\%). *Numerical rating scale (NRS) score of $\geq 4$ to $<6$; ${ }^{\dagger}$ NRS score of 6 or higher. BMI Body mass index; IR Immediate release

were performed and nominal $\mathrm{P}$ values are presented. The percentage of treatment days that a patient reported specific TEAEs was calculated for each treatment and age group using the following formula:

$$
\% \text { treatment days }=100 \times \text { TEAE duration/duration of treatment }
$$

The duration of treatment was defined as follows:

Treatment duration $=$ day of last dose - day of first dose +1

Treatment and age groups were compared using Wilcoxon's rank-sum test.

Between-treatment group and between-age group differences in efficacy were evaluated using an ANCOVA model. In this model, an indicator variable with four levels was included to represent four cell means (one for each of the four combinations of treatment and age groups). The model also included country and previous opioid experience (yes/no) as factors, and baseline pain intensity score as a covariate. Pairwise efficacy differences were estimated based on the least squares mean difference from baseline.

\section{RESULTS}

Patient demographics and disposition

Data from 849 patients who were randomly assigned (4:1 ratio) to receive tapentadol IR or oxycodone IR were included in the present post hoc analyses. Of these patients, 23.3\% (158/679) who received tapentadol IR and 26.5\% (45/170) who received oxycodone IR were at least 65 years of age, and $6.5 \%(44 / 679)$ and $5.3 \%(9 / 170)$ were at least 75 years of age. Demographic and baseline clinical characteristics were comparable between treatment groups (17) and remained comparable when categorized by age (Table 1).

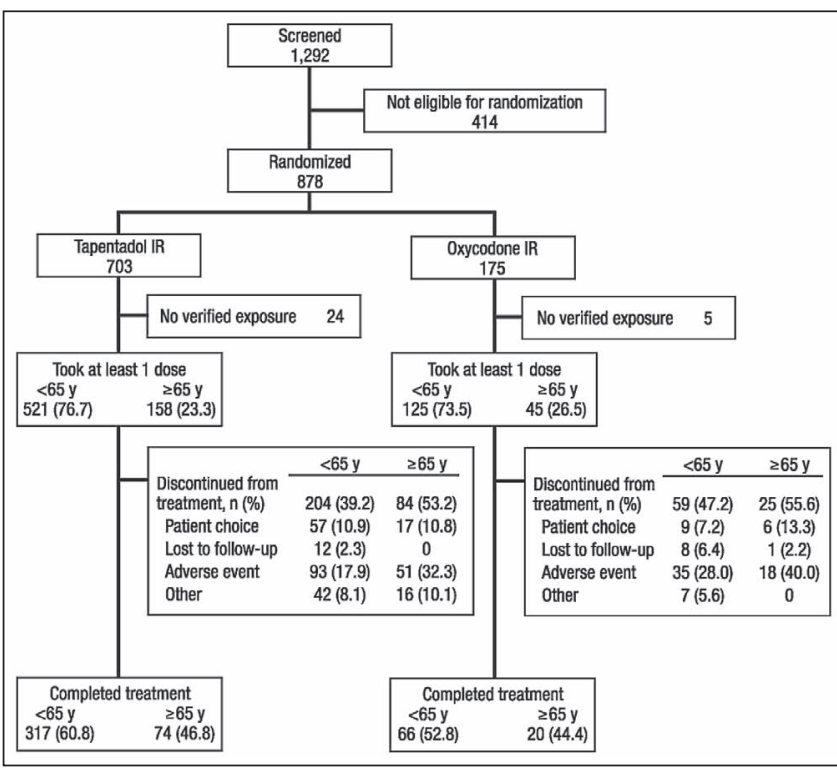

Figure 1) Patient disposition. Data presented as $n$ (\%) unless otherwise indicated. IR Immediate release; y Years of age. Adapted with permission from Informa Healthcare (reference 32)

The overall percentage of patients who discontinued treatment early was $42.4 \%(288 / 679)$ in the tapentadol IR group and $49.4 \%$ $(84 / 170)$ in the oxycodone IR group (17). AEs were the most common reason for treatment discontinuation, with $21.2 \%(144 / 679)$ of patients who received tapentadol IR and 31.2\% (53/170) of patients who received oxycodone IR experiencing an AE leading to treatment discontinuation (17). When patients were analyzed according to age, $39.2 \%(204 / 521)$ of nonelderly and $53.2 \%(84 / 158)$ of elderly patients in the tapentadol IR group, and $47.2 \%(59 / 125)$ of nonelderly and $55.6 \%(25 / 45)$ of elderly patients in the oxycodone IR group discontinued treatment (Figure 1). AEs led to treatment discontinuation for $17.9 \%(93 / 521)$ of nonelderly patients who received tapentadol IR compared with $28.0 \%$ (35/125) of nonelderly patients who received oxycodone IR $(\mathrm{P}=0.013)$. For patients who received tapentadol IR, a significantly higher percentage of elderly patients discontinued treatment because of an AE (32.3\% [51/158]) compared with nonelderly patients $(17.9 \%$ [93/521]; $\mathrm{P}<0.05)$; for patients who received oxycodone IR, $40.0 \%(18 / 45)$ of elderly patients and $28.0 \%(35 / 125)$ of nonelderly patients discontinued because of an AE. There was no significant between-treatment difference in the rate of discontinuation due to an AE for elderly patients who received either tapentadol IR (32.3\% [51/158]) or oxycodone IR (40.0\% [18/45]; P=0.374).

\section{Tolerability}

Study discontinuation due to TEAEs: These post hoc analyses evaluated the incidence of study discontinuation and the time to discontinuation due to one or more TEAEs. Overall, 20.8\% (141/679) of patients who received tapentadol IR discontinued from the study because of TEAEs compared with 30.6\% (52/170) of patients who received oxycodone IR $(\mathrm{P}=0.008)$; the majority of these discontinuations were due to gastrointestinal-related TEAEs (8.8\% [60/679] versus $21.2 \%$ [36/170] for tapentadol IR and oxycodone IR, respectively) (17). The incidences of study discontinuation due to TEAEs for patients in both age groups who received tapentadol IR and oxycodone IR are shown in Table 2 . The majority of study discontinuations in both treatment groups were due to gastrointestinal- and nervous system-related TEAEs (Table 2).

Overall, patients who received tapentadol IR remained in the study longer than patients who received oxycodone IR. Among nonelderly patients, the time to discontinuation due to any TEAE was significantly later for those who received tapentadol IR 
TABLE 2

Study discontinuations due to treatment-emergent adverse events (TEAEs) in at least $5 \%$ of patients in any treatment group and corresponding incidence according to age*

\begin{tabular}{lcclcc}
\hline & \multicolumn{2}{c}{$<65$ years of age } & & \multicolumn{2}{c}{$\geq 65$ years of age } \\
\cline { 2 - 3 } \cline { 6 - 7 } TEAE & $\begin{array}{c}\text { Tapentadol } \\
\text { IR }(\mathbf{n}=521)\end{array}$ & $\begin{array}{c}\text { Oxycodone } \\
\text { IR }(\mathbf{n}=\mathbf{1 2 5})\end{array}$ & & $\begin{array}{c}\text { Tapentadol } \\
\text { IR }(\mathbf{n}=158)\end{array}$ & $\begin{array}{c}\text { Oxycodone } \\
\text { IR }(\mathbf{n}=\mathbf{4 5})\end{array}$ \\
\hline Any TEAE $^{\dagger}$ & $91(17.5)$ & $35(28.0)$ & & $50(31.6)$ & $17(37.8)$ \\
All GI-related TEAES & $35(6.7)$ & $25(20.0)$ & & $25(15.8)$ & $11(24.4)$ \\
Nausea & $21(4.0)$ & $14(11.2)$ & & $12(7.6)$ & $4(8.9)$ \\
Constipation & $3(0.6)$ & $5(4.0)$ & & $7(4.4)$ & $5(11.1)$ \\
Vomiting & $9(1.7)$ & $11(8.8)$ & & $9(5.7)$ & $3(6.7)$ \\
All NS-related TEAEs & $36(6.9)$ & $16(12.8)$ & & $22(13.9)$ & $8(17.8)$ \\
Dizziness & $14(2.7)$ & $5(4.0)$ & & $14(8.9)$ & $5(11.1)$ \\
\hline
\end{tabular}

Data presented as $n$ (\%). *Patients could report more than one TEAE as their reason for discontinuation; ${ }^{\dagger}$ Four patients who were listed as discontinuing treatment due to an adverse event in Figure 1 are not included in this table because of missing information for "Action Taken with Study Treatment" in the TEAE report (tapentadol immediate release [IR]: younger than 65 years of age [ $n=1]$, 65 years of age or older [ $n=1]$; oxycodone IR: 65 years of age or older $[n=1]$ ) or no TEAE report (tapentadol IR: younger than 65 years of age $[n=1]$ ). GI Gastrointestinal; NS Nervous system

compared with oxycodone IR $(\mathrm{P}=0.006)$; for elderly patients, there was no significant difference in time to discontinuation due to any TEAE between treatment groups $(\mathrm{P}=0.379$; Figure 2A). Among patients who received tapentadol IR, elderly patients were discontinued from the study earlier than nonelderly patients because of a
TEAE $(\mathrm{P}<0.001)$; the difference in time to discontinuation due to a TEAE was not significant between age groups for patients who received oxycodone IR $(\mathrm{P}=0.196)$.

With respect to study discontinuation due to the specific TEAEs of nausea and vomiting, a later time to discontinuation was observed for nonelderly patients who received tapentadol IR compared with patients who received oxycodone IR for discontinuations due to nausea $(\mathrm{P}=0.001$; Figure $2 \mathrm{~B})$ and vomiting $(\mathrm{P}<0.001$; Figure $2 \mathrm{C})$. Among elderly patients, there were no statistically significant differences in the times to study discontinuation due to nausea $(\mathrm{P}=0.564)$ or vomiting $(\mathrm{P}=0.773)$ between treatment groups.

For the specific TEAE of constipation, a later time to discontinuation due to constipation was observed for nonelderly patients who received tapentadol IR compared with oxycodone IR ( $\mathrm{P}=0.002$; Figure 2D). Among elderly patients, there was no statistically significant difference between treatment groups in the time to study discontinuation due to constipation $(\mathrm{P}=0.055)$.

\section{TEAEs}

The incidences of TEAEs were compared within treatment groups according to age and within age groups according to treatment (Table 3). Among elderly patients, the incidence of pruritus $(3.2 \%$ [5/158] versus $13.3 \%$ [6/45]) and the composite incidence of nausea or vomiting (30.4\% [48/158] versus 51.1\% [23/45]) were significantly lower with tapentadol IR compared with oxycodone IR $(\mathrm{P}<0.05$ for both). The incidences of these TEAEs showed a similar pattern with lower incidences for nonelderly patients who received tapentadol IR versus oxycodone IR, respectively (pruritus: 4.6\% [24/521] versus $11.2 \%$ [14/125]; composite of nausea or vomiting: $27.3 \%[142 / 521]$ versus 44.0\% [55/125]; $\mathrm{P}<0.05$ for both). Additionally, the incidence

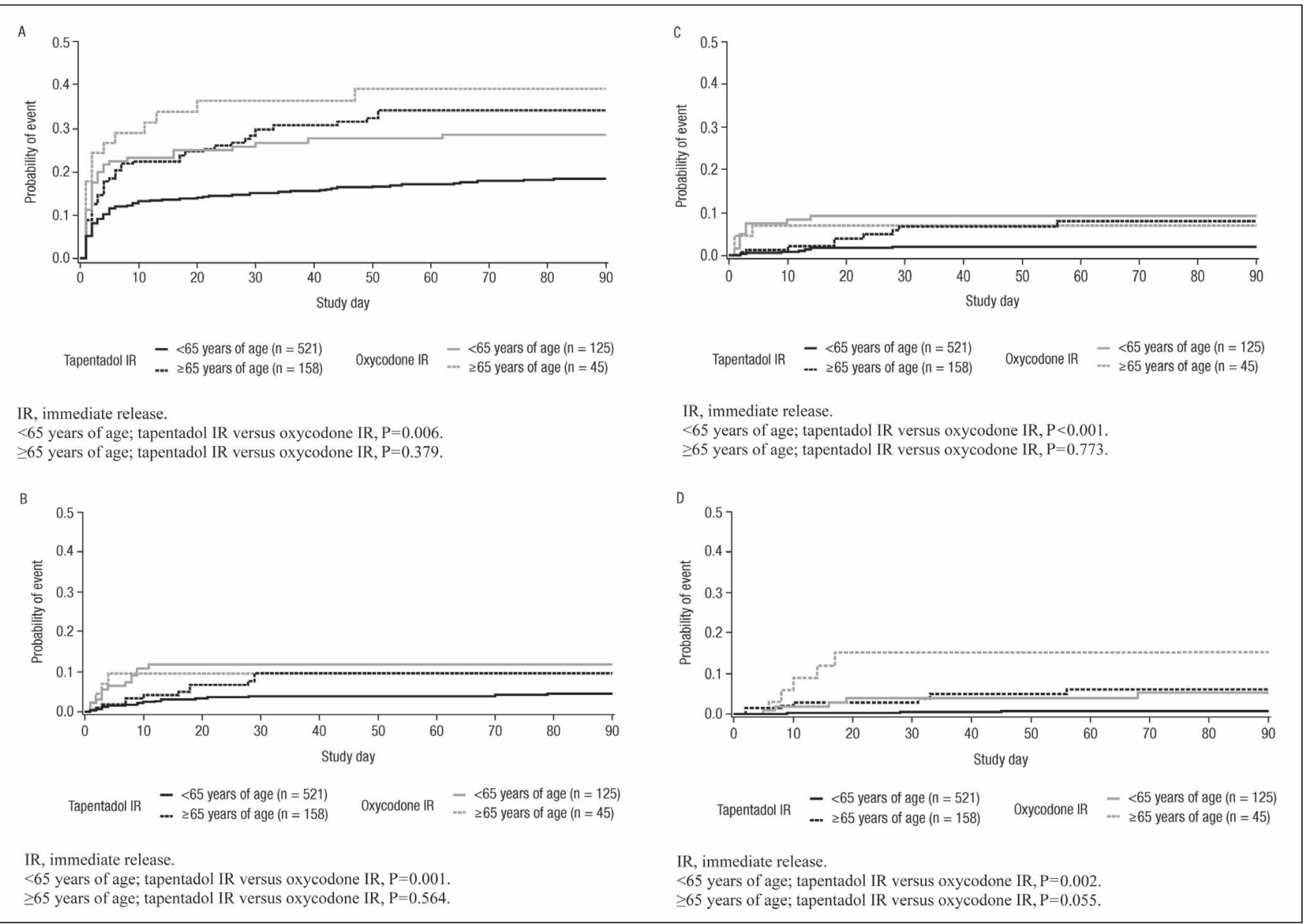

Figure 2) Time to study discontinuation due to any treatment-emergent adverse event (A), nausea (B), vomiting (C) and constipation (D) 
TABLE 3

Treatment-emergent adverse events (TEAEs) in at least $5 \%$ of patients in any treatment group and corresponding incidence according to age

\begin{tabular}{|c|c|c|c|c|}
\hline \multirow[b]{2}{*}{ TEAE } & \multicolumn{2}{|c|}{$<65$ years of age } & \multicolumn{2}{|c|}{$\geq 65$ years of age } \\
\hline & $\begin{array}{l}\text { Tapentadol } \\
\text { IR }(n=521)\end{array}$ & $\begin{array}{l}\text { Oxycodone } \\
\text { IR }(n=125)\end{array}$ & $\begin{array}{l}\text { Tapentadol } \\
\text { IR }(n=158)\end{array}$ & $\begin{array}{c}\text { Oxycodon } \\
\text { IR }(n=45)\end{array}$ \\
\hline Any TEAE & $396(76.0)$ & $101(80.8)$ & $122(77.2)$ & $40(88.9)$ \\
\hline Nausea & $91(17.5)^{\star}$ & $34(27.2)$ & 34 (21.5) & $16(35.6)$ \\
\hline Constipation & $57(10.9)^{*}$ & $30(24.0)$ & $30(19.0)^{\dagger}$ & $16(35.6)$ \\
\hline Vomiting & $90(17.3)^{*}$ & $40(32.0)$ & 25 (15.8) & $11(24.4)$ \\
\hline Dizziness & $79(15.2)$ & $15(12.0)$ & $44(27.8)$ & $14(31.1)$ \\
\hline Pruritus & $24(4.6)^{*}$ & $14(11.2)$ & $5(3.2)^{\dagger}$ & $6(13.3)$ \\
\hline Somnolence & $49(9.4)$ & $11(8.8)$ & $20(12.7)$ & 5 (11.1) \\
\hline Headache & $65(12.5)$ & 14 (11.2) & $13(8.2)$ & $3(6.7)$ \\
\hline Dry mouth & $22(4.2)$ & $3(2.4)$ & $14(8.9)$ & $2(4.4)$ \\
\hline Diarrhea & $34(6.5)$ & $8(6.4)$ & $11(7.0)$ & $2(4.4)$ \\
\hline Insomnia & $24(4.6)$ & $4(3.2)$ & $5(3.2)$ & $3(6.7)$ \\
\hline Abdominal pain & $6(1.2)$ & $4(3.2)$ & $6(3.8)$ & $3(6.7)$ \\
\hline Fatigue & $30(5.8)$ & $3(2.4)$ & $8(5.1)$ & $1(2.2)$ \\
\hline
\end{tabular}

Data presented as $n(\%)$. *Younger than 65 years of age: tapentadol immediate release (IR) versus oxycodone IR, Fisher's exact test, nominal $P<0.05$; ${ }^{\dagger} 65$ years of age or older: tapentadol IR versus oxycodone IR, Fisher's exact test, nominal $P<0.05$

of constipation was significantly lower for patients who received tapentadol IR than for those who received oxycodone IR regardless of age (elderly: $19.0 \%$ [30/158] versus $35.6 \%$ [16/45]; nonelderly: $10.9 \%$ [57/521] versus 24.0\% [30/125]; $\mathrm{P}<0.05$ for both [Table 3]); among elderly patients, $0.6 \%(1 / 158)$ of patients who received tapentadol IR and $11.1 \%$ (5/45) of those who received oxycodone IR experienced severe constipation (Figure 3 ).

Although there were no unusual TEAEs experienced by elderly patients, these patients experienced a higher overall incidence of TEAEs compared with nonelderly patients, regardless of their assigned treatment group. Within the tapentadol IR treatment group, nonelderly patients had significantly lower incidences of constipation $(10.9 \%$ [57/521] versus $19.0 \%$ [30/158]), dizziness (15.2\% [79/521] versus $27.8 \%$ [44/158]) and dry mouth (4.2\% [22/521] versus 8.9\% [14/158]; $\mathrm{P}<0.05$ for all) compared with elderly patients; the between-age group differences in the incidences of diarrhea, fatigue, insomnia, headache, nausea, pruritus, somnolence and vomiting were not statistically significant (Table 3). Within the oxycodone IR treatment group, nonelderly patients had significantly lower incidences of dizziness (12.0\% [15/125]) than elderly patients $(31.1 \%$ [14/45]; $\mathrm{P}<0.05)$; all other differences in the incidences of specific TEAEs between age groups within the oxycodone IR treatment group were not statistically significant.

As a measure of the overall burden of a TEAE on patients, the percentage of treatment days during which patients experienced nausea, vomiting, constipation, dizziness and pruritus was evaluated (Figure 4). Patients who received tapentadol IR reported a lower percentage of treatment days with pruritus compared with oxycodone IR, regardless of age (nonelderly: $2.3 \%$ versus $6.4 \%$, respectively [P=0.004]; elderly: $2.0 \%$ versus $9.1 \%$, respectively $[\mathrm{P}=0.008]$ ). Elderly patients who received tapentadol IR experienced constipation for a significantly lower percentage of treatment days $(10.3 \%)$ compared with patients who received oxycodone IR $(19.6 \% ; \mathrm{P}=0.020)$.

\section{Efficacy}

Although efficacy was not a primary end point for the present study, efficacy data from the trial were reported previously (17). The data showed that tapentadol IR $50 \mathrm{mg}$ or $100 \mathrm{mg}$ and oxycodone $\mathrm{HCl}$ IR $10 \mathrm{mg}$ or $15 \mathrm{mg}$ administered every $4 \mathrm{~h}$ to $6 \mathrm{~h}$, as needed, provided similar levels of pain relief. The mean $( \pm$ SD) pain intensity scores decreased from baseline scores of $7.0 \pm 1.60$ and $7.2 \pm 1.40$ to $4.9 \pm 2.42$

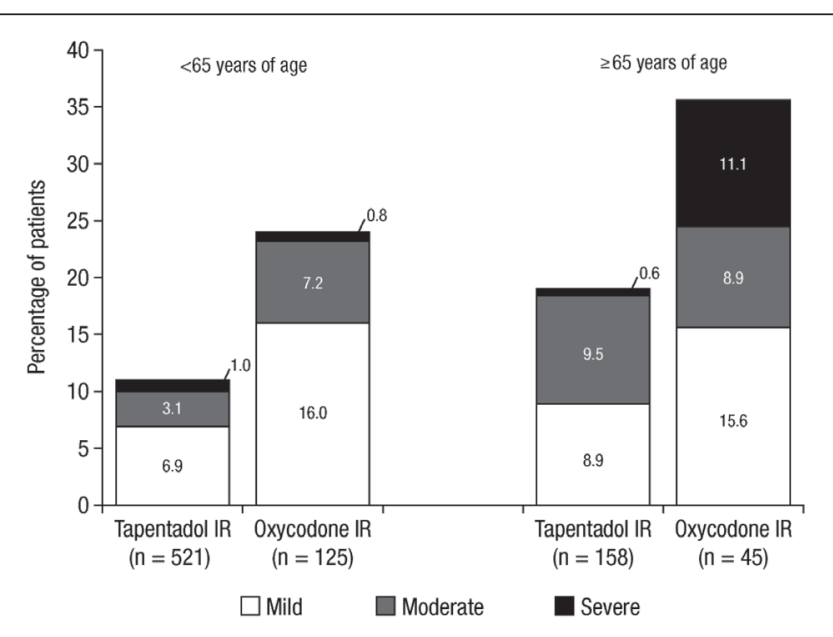

Figure 3) Incidence of constipation according to intensity, age group and treatment. IR Immediate release

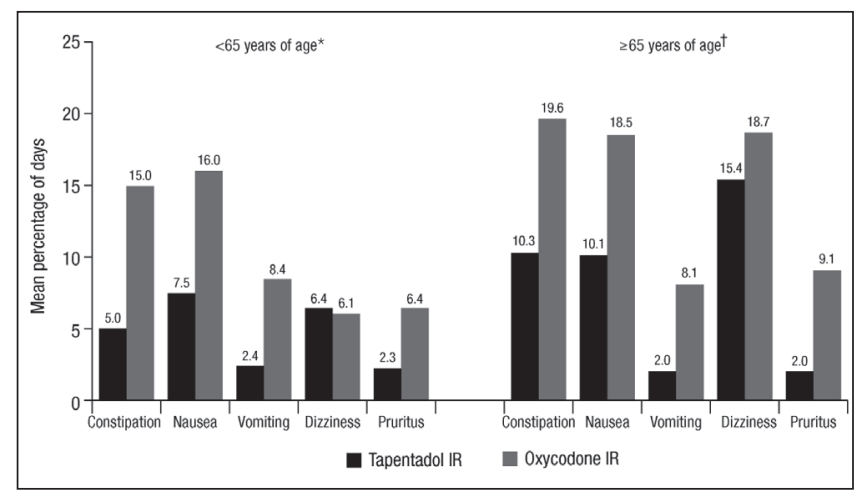

Figure 4) Mean percentage of treatment days during which patients experienced constipation, nausea, vomiting, dizziness and pruritus (among patients who experienced the treatment-emergent adverse events of constipation, nausea, vomiting, dizziness and pruritus). *Tapentadol immediate release (IR $[n=521])$; oxycodone IR $(n=125)$; †Tapentadol IR $(n=158)$; oxycodone IR $(n=45)$

and $5.2 \pm 2.40$ at the end of the study for patients in the tapentadol IR and oxycodone IR groups, respectively (17). Mean pain intensity scores decreased during the first 15 days of treatment for all patients and then remained relatively stable from day 29 onward, ranging from $3.8 \pm 2.06$ to $5.4 \pm 2.32$. In the post hoc analyses, mean pain intensity scores at baseline were similar across treatment and age groups, ranging from $7.0 \pm 1.76$ to $7.2 \pm 1.69$. When evaluating according to age group, the least squares mean $( \pm \mathrm{SE})$ change between treatment groups from baseline to end point in the mean pain intensity score was not significantly different for nonelderly patients (tapentadol IR: $-1.70 \pm 0.26$; oxycodone IR: $-1.36 \pm 0.31[\mathrm{P}=0.133]$ ) or for elderly patients (tapentadol IR: $-1.57 \pm 0.29$; oxycodone IR: $-1.36 \pm 0.42$; $\mathrm{P}=0.603$ ). There were no overall age-dependent differences in efficacy observed among patients, regardless of treatment group $(\mathrm{P}=0.987$ for nonelderly versus elderly patients in the oxycodone IR group; $\mathrm{P}=0.521$ for nonelderly versus elderly patients in the tapentadol IR group).

Exposure to study medication

As part of these post hoc analyses, treatment exposure to study medication was evaluated according to age category. Elderly and nonelderly patients, respectively, received mean total daily doses of $235.6 \pm 119.7 \mathrm{mg}$ and $298.4 \pm 163.1 \mathrm{mg}$ of tapentadol IR, and $33.7 \pm 18.0 \mathrm{mg}$ and $44.9 \pm 26.5 \mathrm{mg}$ of oxycodone IR. 
Concomitant medication and newly initiated stool softener use Overall, 96.6\% (196/203) of elderly patients and 95.2\% (615/646) of nonelderly patients used concomitant medications; nonanalgesic medications were used by $96.1 \%$ (195/203) of elderly patients and by $83.9 \%$ (542/646) of nonelderly patients. In addition, $12.0 \%$ (19/158) of elderly patients who received tapentadol IR started using laxatives and/or stool softeners after random assignment to a treatment group compared with $22.2 \%(10 / 45)$ who received oxycodone IR ( $\mathrm{P}=0.0944)$.

\section{DISCUSSION}

Elderly patients are more susceptible to adverse effects associated with opioid analgesics $(3,20,21)$, which is important for clinicians to consider when initiating treatment with opioids in this patient population. Despite this, there are few published studies addressing the tolerability-related issues associated with the use of opioids in elderly patients, and practice recommendations are based on extrapolation from younger patients and limited available information pertaining to the pharmacokinetics of opioids in older patients $(8,22,23)$. Results from these post hoc data analyses showed that the safety profiles of tapentadol IR and oxycodone IR were qualitatively similar and typical for drugs with $\mu$-opioid receptor agonist activity (24). Among the most commonly reported TEAEs, no unique AEs were observed in elderly patients compared with nonelderly patients; however, significant quantitative differences were observed between treatment groups, with lower percentages of elderly patients treated with tapentadol IR reporting TEAEs of constipation or the composite of nausea or vomiting versus those treated with oxycodone IR.

In these post hoc analyses, patients who received tapentadol IR experienced lower incidences of TEAEs than patients who received oxycodone IR, regardless of age; elderly patients experienced a higher incidence of TEAEs than nonelderly patients for both the oxycodone IR and tapentadol IR treatment groups. These results are consistent with those observed in a meta-analysis of several commonly prescribed opioids (25), which found significantly greater incidences of nausea, vomiting and constipation among elderly patients compared with younger patients. Among elderly patients in the current analysis, those who received tapentadol IR (50 mg or $100 \mathrm{mg}$ every $4 \mathrm{~h}$ to $6 \mathrm{~h}$ as needed) had significantly lower incidences of gastrointestinalrelated TEAEs than those who received oxycodone HCl IR (10 mg to $15 \mathrm{mg}$ every $4 \mathrm{~h}$ to $6 \mathrm{~h}$ as needed).

The true clinical impact of an AE may not be adequately reflected solely in the incidences of the side effect. The impact of AEs as measured by the amount of time that patients experience these AEs and whether AEs lead to discontinuation are important factors to consider. Among younger patients, tapentadol IR was associated with a lower percentage of treatment days during which patients experienced gastrointestinalrelated TEAEs compared with oxycodone IR. In addition, the percentage of treatment days during which patients experienced pruritus was lower in the tapentadol IR group than in the oxycodone IR group, regardless of age. Patients who received tapentadol IR also remained in the study longer than patients who received oxycodone IR.

The risk for opioid-induced constipation must be considered when initiating treatment in elderly patients because, as a group, elderly patients generally experience a higher rate of constipation compared with younger patients $(11,26)$. Constipation is the most commonly reported gastrointestinal complaint of elderly people, with up to $60 \%$ of elderly outpatients reporting laxative use (26). This is due, in part, to age-related changes in anorectal physiology that predispose older patients to problems including increased rectal compliance, impaired rectal sensation, decreased resting and anal sphincter pressure, and decreased maximal sphincter pressure (26). Patients may develop tolerance to many side effects of opioids within days of initiation of drug therapy; however, they typically do not develop tolerance to constipation (24); this side effect often leads to discontinuation of medication if not successfully treated. In the present study, elderly patients who received oxycodone IR reported a higher incidence of constipation, especially constipation of severe intensity, and a higher percentage of treatment days with constipation than the tapentadol IR group, despite a numerically higher percentage of elderly patients treated with oxycodone IR initiating laxative and/or stool softener use during the study. In the present study, tapentadol IR exhibited better tolerability, with respect to constipation, among elderly patients compared with oxycodone IR.

The present study also found that elderly patients treated with tapentadol IR had significantly higher incidences of the dizziness and dry mouth TEAEs compared with nonelderly patients. These results are consistent with the higher prevalence of these AEs in the general elderly population compared with younger people. Among the elderly, the prevalence of chronic dizziness is estimated to be between $13 \%$ and $30 \%$, and dry mouth is a common complaint among elderly patients, caused in part by increased use of anticholinergic and diuretic drugs, radiotherapy and higher incidences of conditions including Alzheimer's disease and diabetes mellitus $(27,28)$.

Although efficacy was not the primary end point of the original study (17), efficacy comparisons were undertaken to allow for a more clinically meaningful comparison of the tolerability profiles and to explore any clinically relevant differences in efficacy between younger and older patients. Improvements in pain intensity reported by patients in the original study (17) suggested that tapentadol IR (50 mg or $100 \mathrm{mg}$ every $4 \mathrm{~h}$ to $6 \mathrm{~h}$ as needed) and oxycodone HCl IR ( $10 \mathrm{mg}$ or $15 \mathrm{mg}$ every $4 \mathrm{~h}$ to $6 \mathrm{~h}$ as needed) provided similar pain relief over 90 days, which enabled a comparison of tolerability between these doses. The results of these post hoc analyses confirm the findings of the original study of the overall population, and also demonstrate that tapentadol IR has a better gastrointestinal tolerability profile than oxycodone IR for nonelderly patients and elderly patients. Baseline pain intensity scores were comparable for nonelderly and elderly patients, and no overall differences in efficacy were observed between patients regardless of treatment group.

In general, elderly patients tend to report a higher incidence of side effects and under-report pain, and they are more likely to be on a variety of concomitant medications compared with younger patients (3). In the present study, overall exposure to study medication, in terms of both mean total daily dose and the amount of time patients remained in the study, was lower for elderly patients than for nonelderly patients in both treatment groups; therefore, the higher incidence of TEAEs observed for elderly patients in the present study was not associated with an overall increase in exposure to study medication. Despite this lower exposure to study medication, elderly patients reported levels of baseline pain and reductions in pain intensity over the course of the study that were similar to the levels reported by younger patients. It is important to note that while elderly patients in the present study used more concomitant medications than younger patients, no analyses were performed to determine whether the categories of concomitant medications used in the study are reflective of medication use in the general elderly population $(29,30)$.

One limitation of these post hoc analyses is that the original study (17) was not powered for comparisons between subpopulations, and no adjustments were made for multiple comparisons in the post hoc analyses. In addition, the relatively small sample size of elderly patients was a limitation, especially for patients who received oxycodone IR because of the 4:1 random assignment ratio. However, results of these analyses are consistent with the observed side effects associated with oxycodone IR in healthy middle-age ( 35 to 55 years) versus older (older than 65 years) adults reported by Cherrier et al (31). In that study (31), the occurrence of side effects associated with oxycodone IR was similar between middleage and older adults, with the minor exception of older adults experiencing increased dizziness, feeling less energetic and less elated compared with their younger counterparts.

Results of these analyses further extend the observations from shorter-term studies that demonstrated that patients who received tapentadol IR ( $50 \mathrm{mg}, 75 \mathrm{mg}$ or $100 \mathrm{mg}$ every $4 \mathrm{~h}$ to $6 \mathrm{~h}$ ) reported better gastrointestinal tolerability than patients who received oxycodone $\mathrm{HCl}$ IR (10 mg or $15 \mathrm{mg}$ every $4 \mathrm{~h}$ to $6 \mathrm{~h}$ ) (14-16). The better gastrointestinal tolerability profile observed with the regimen of tapentadol IR used in the present study was associated with patients remaining on 
treatment for a longer period of time compared with patients who received oxycodone IR. Therefore, the use of tapentadol IR may enable patients to stay on treatment for longer periods of time compared with oxycodone IR, and elderly patients treated with tapentadol IR may have an increased likelihood of achieving better overall relief of moderate to severe lower back pain or osteoarthritis pain.

ACKNOWLEDGEMENTS: Editorial support for the writing of this manuscript was provided by John Togneri, of MedErgy HealthGroup (USA). The authors thank Dr Jianhong Lu for providing statistical programming support.

FINANCIAL SUPPORT: This study was funded by Janssen Scientific Affairs, LLC (USA), and Global Development, Grünenthal GmbH (Aachen, Germany). The authors retained full editorial control over the content of the manuscript.

\section{REFERENCES}

1. Barkin RL, Barkin SJ, Barkin DS. Perception, assessment, treatment, and management of pain in the elderly. Clin Geriatr Med 2005;21:465-90.

2. Chodosh J, Solomon DH, Roth CP, et al. The quality of medical care provided to vulnerable older patients with chronic pain. J Am Geriatr Soc 2004;52:756-61.

3. Gloth FM, III. Pain management in older adults: Prevention and treatment. J Am Geriatr Soc 2001;49:188-99.

4. Devereaux MW. Low back pain. Prim Care 2004;31:33-51.

5. Avouac J, Gossec L, Dougados M. Efficacy and safety of opioids for osteoarthritis: A meta-analysis of randomized controlled trials. Osteoarthritis Cartilage 2007;15:957-65.

6. Chou R, Qaseem A, Snow V, et al. Diagnosis and treatment of low back pain: A joint clinical practice guideline from the American College of Physicians and the American Pain Society. Ann Intern Med 2007;147:478-91.

7. Auret K, Schug SA. Underutilisation of opioids in elderly patients with chronic pain: Approaches to correcting the problem. Drugs Aging 2005;22:641-54.

8. Chapter 43: Pain. In: The Merck Manual of Geriatrics. New Jersey: Merck Sharpe \& Dohme Corp. <www.merck.com/mkgr/mmg/sec6/ ch43/ch43a.jsp> (Accessed on November 30, 2009).

9. Kalso E, Edwards JE, Moore RA, McQuay HJ. Opioids in chronic non-cancer pain: Systematic review of efficacy and safety. Pain 2004;112:372-80.

10. Bannwarth B. Risk-benefit assessment of opioids in chronic noncancer pain. Drug Saf 1999;21:283-96.

11. Schaefer DC, Cheskin LJ. Constipation in the elderly. Am Fam Physician 1998;58:907-14.

12. American Geriatrics Society Panel on the Pharmacological Management of Persistent Pain in Older Persons. Pharmacological management of persistent pain in older persons. J Am Geriatr Soc 2009;57:1331-46

13. Tzschentke TM, De Vry J, Terlinden R, et al. Tapentadol HCl. Drugs Future 2006;31:1053-61.

14. Daniels S, Casson E, Stegmann JU, et al. A randomized, double-blind, placebo-controlled phase 3 study of the relative efficacy and tolerability of tapentadol IR and oxycodone IR for acute pain. Curr Med Res Opin 2009;25:1551-61.

15. Daniels SE, Upmalis D, Okamoto A, Lange C, Haeussler J. A randomized, double-blind, phase III study comparing multiple doses of tapentadol IR, oxycodone IR, and placebo for postoperative (bunionectomy) pain. Curr Med Res Opin 2009;25:765-76.

16. Hartrick C, Van Hove I, Stegmann J-U, Oh C, Upmalis D. Efficacy and tolerability of tapentadol immediate release and oxycodone $\mathrm{HCl}$ immediate release in patients awaiting primary joint replacement surgery for end-stage joint disease: A 10-day, phase III, randomized, double-blind, active- and placebo-controlled study. Clin Ther 2009;31:260-71.

17. Hale M, Upmalis D, Okamoto A, Lange C, Rauschkolb C. Tolerability of tapentadol immediate release in patients with lower back pain or osteoarthritis of the hip or knee over 90 days: A randomized, double-blind study. Curr Med Res Opin 2009;25:1095-104.

18. US Census Bureau. Statistical Brief. Sixty-five plus in the United States. May 1995. Economics and Statistics Administration, U.S. Department of Commerce. <www.census.gov/population/socdemo/ statbriefs/agebrief.html> (Accessed on June 14, 2010).

19. World Health Organization. Definition of an older or elderly person. <www.who.int/healthinfo/survey/ageingdefnolder/en/index. html $>$ (Accessed on June 14, 2010).

20. Ferrell BA. Pain evaluation and management in the nursing home. Ann Intern Med 1995;123:681-7.

21. Forman WB. Opioid analgesic drugs in the elderly. Clin Geriatr Med 1996;12:489-500.

22. Pergolizzi J, Boger RH, Budd K, et al. Opioids and the management of chronic severe pain in the elderly: Consensus statement of an International Expert Panel with focus on the six clinically most often used World Health Organization Step III opioids (buprenorphine, fentanyl, hydromorphone, methadone, morphine, oxycodone). Pain Pract 2008;8:287-313.

23. American Geriatrics Society Panel on Persistent Pain in Older Persons. The management of persistent pain in older persons. J Am Geriatr Soc 2002;50:S205-24.

24. Benyamin R, Trescot AM, Datta S, et al. Opioid complications and side effects. Pain Physician 2008;11:S105-20.

25. Goldstein DJ, Turk DC. Dextropropoxyphene: Safety and efficacy in older patients. Drugs Aging 2005;22:419-32.

26. Chapter 110: Constipation, diarrhea, and fecal incontinence. In: The Merck Manual of Geriatrics. New Jersey: Merck Sharpe \& Dohme Corp. <www.merck.com/mkgr/mmg/sec13/ch110/ch110a. jsp\#ind13-110-7121> (Accessed on November 30, 2009).

27. Chapter 19: Chronic dizziness and postural instability. In: The Merck Manual of Geriatrics. New Jersey: Merck Sharpe \& Dohme Corp. <www.merck.com/mkgr/mmg/sec2/ch19/ch19a. jsp\#ind02-019-1210> (Accessed on November 30, 2009).

28. Chapter 104: Dental and oral disorders. In: The Merck Manual of Geriatrics. <www.merck.com/mkgr/mmg/sec13/ch104/ch104a. jsp\#ind13-104-6664> (Accessed on November 30, 2009).

29. Linton A, Garber M, Fagan NK, Peterson MR. Examination of multiple medication use among TRICARE beneficiaries aged 65 years and older. J Manag Care Pharm 2007;13:155-62.

30. Rathore SS, Mehta SS, Boyko WL Jr, Schulman KA. Prescription medication use in older Americans: A national report card on prescribing. Fam Med 1998;30:733-9.

31. Cherrier MM, Amory JK, Ersek M, Risler L, Shen DD. Comparative cognitive and subjective side effects of immediate-release oxycodone in healthy middle-aged and older adults. J Pain 2009;10:1038-50.

32. Hale M, Upmalis D, Okamoto A, Lange C, Rauschkolb C. Tolerability of tapentadol immediate release in patients with lower back pain or osteoarthritis of the hip or knee over 90 days: A randomized, double-blind study. Curr Med Res Opin 2009;25:1095-104. 


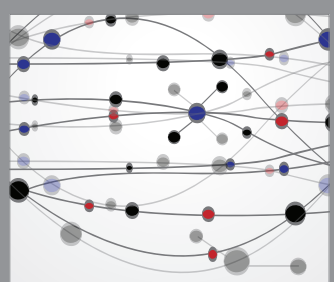

The Scientific World Journal
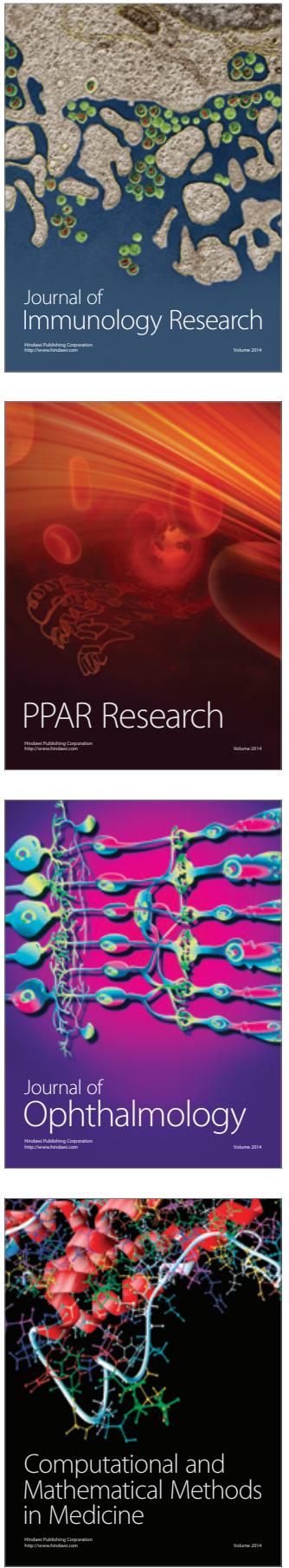

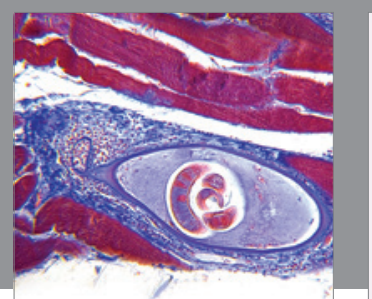

Gastroenterology Research and Practice

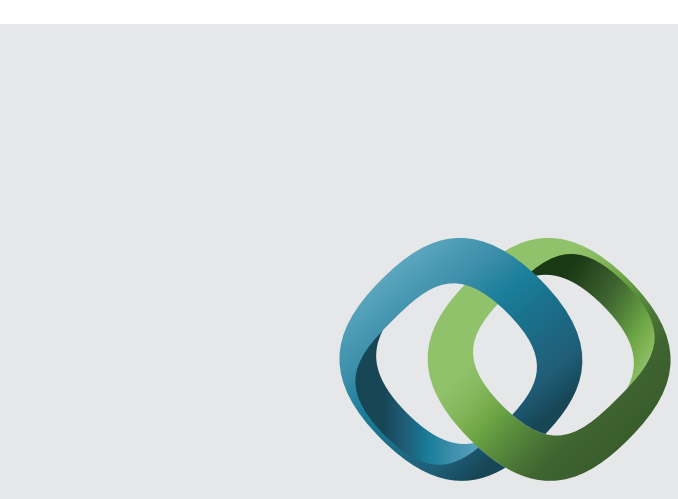

\section{Hindawi}

Submit your manuscripts at

http://www.hindawi.com
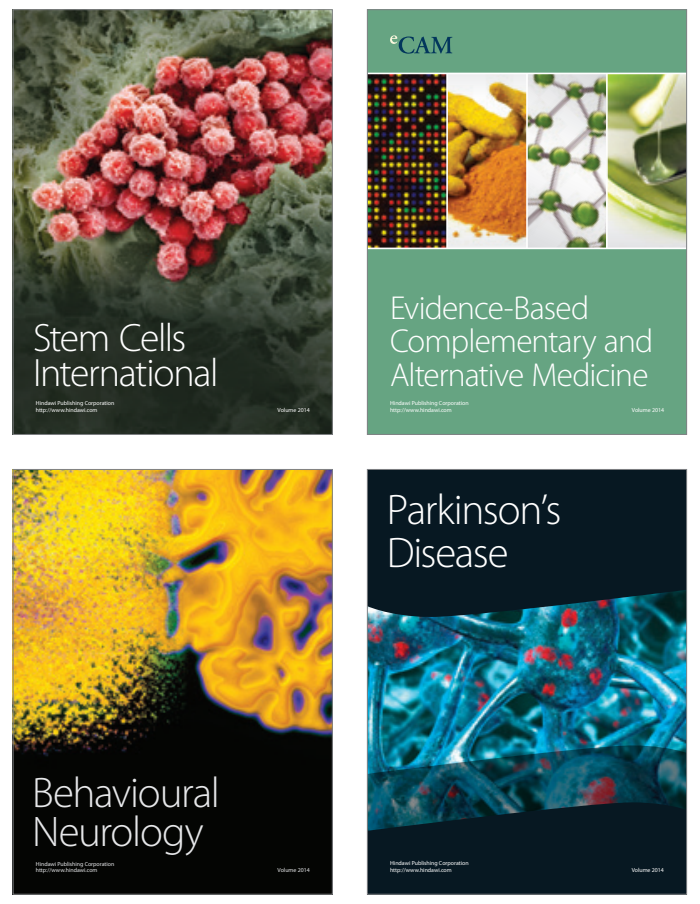
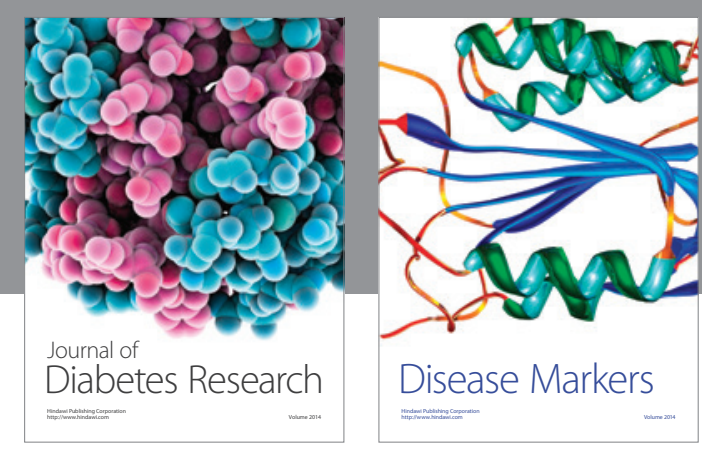

Disease Markers
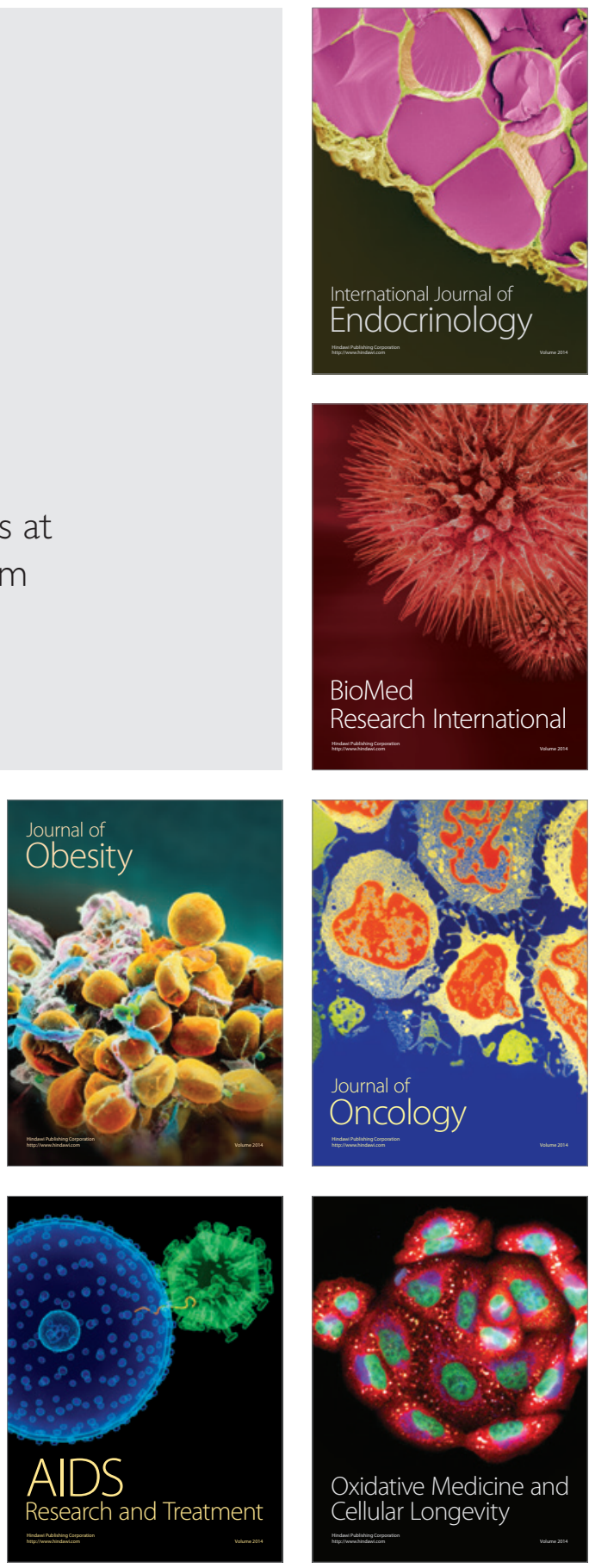